Bond University

Research Repository

\title{
Validation of the adaptive reuse potential (ARP) model using iconCUR
}

\author{
Langston, Craig
}

Published in:

Facilities

DOI:

$10.1108 / 02632771211202824$

Licence:

CC BY-NC-ND

Link to output in Bond University research repository.

Recommended citation(APA):

Langston, C. (2012). Validation of the adaptive reuse potential (ARP) model using iconCUR. Facilities, 30(3-4), 105-123. https://doi.org/10.1108/02632771211202824

\section{General rights}

Copyright and moral rights for the publications made accessible in the public portal are retained by the authors and/or other copyright owners and it is a condition of accessing publications that users recognise and abide by the legal requirements associated with these rights.

For more information, or if you believe that this document breaches copyright, please contact the Bond University research repository coordinator. 


\section{Bond University}

\section{ePublications@bond}

$2-1-2012$

\section{Validation of the adaptive reuse potential (ARP) model using iconCUR}

Craig Langston

Bond University, craig_langston@bond.edu.au

Follow this and additional works at: http://epublications.bond.edu.au/sustainable_development

Part of the Architectural Technology Commons, Construction Engineering Commons, and the Environmental Design Commons

\section{Recommended Citation}

Craig Langston. (2012) "Validation of the adaptive reuse potential (ARP) model using iconCUR" Facilities, 30 (3-4), 105-123: ISSN 0263-2772.

http://epublications.bond.edu.au/sustainable_development/160 
Validation of the Adaptive Reuse Potential (ARP) Model using iconCUR

Professor Craig Langston

Mirvac School of Sustainable Development

Bond University

Gold Coast, Australia

Corresponding author:

Professor Craig Langston

clangsto@bond.edu.au 


\title{
Validation of the Adaptive Reuse Potential (ARP) Model using iconCUR
}

\author{
Abstract \\ The adaptive reuse of existing buildings that have become obsolete is an important strategy for \\ sustainable development and a pertinent response to excessive resource usage resulting from typical \\ destruction and redevelopment. This paper looks at the validity of earlier work to model adaptive \\ reuse potential (ARP) using a new multiple criteria decision analysis tool called iconCUR. Based on a \\ review of twelve case studies, this paper determines the extent of agreement between ARP and \\ iconCUR evaluations that both claim to be useful in making decisions about reuse. The results show a \\ high correlation between these approaches, whether based on raw scores or on relative ranking, and \\ match expert opinion concerning appropriate actions. This work represents the culmination of a \\ three-year study into the strategic assessment of building adaptive reuse opportunities. It provides \\ confidence in the modeling of future interventions to revitalize existing built assets using a triple \\ bottom line perspective.
}

Keywords: adaptive reuse, intervention, sustainability, adaptive management, multiple criteria decision analysis, facilities management

\section{Introduction}

Existing buildings that are obsolete or rapidly approaching disuse and potential demolition are a 'mine' of raw materials for new projects; a concept described by Chusid (1993) as 'urban ore'. An even more effective solution than raw material recovery is to leave the basic structure and fabric of the building intact, and change its use. This approach is called 'adaptive reuse'. Breathing 'new life' into existing buildings carries with it environmental and social benefits and helps to retain our national heritage. To date, a focus on economic factors alone has contributed to destruction of buildings well short of their physical lives.

Adaptive reuse has great application to international efforts to conserve resources through more sustainable practice. Such actions in turn contribute to lower greenhouse gas emissions and waste and therefore form part of the array of adaptation strategies available to the property sector in the face of global climate change. In the developed world we have seen an increase in the proportion of capital expenditure directed to refurbishment works in recent years, and this now outweighs capital expenditure of new construction in many countries (Douglas, 2006). This trend will continue.

This paper looks at the validity of earlier work to model adaptive reuse potential (ARP) using a new multiple criteria decision analysis tool called iconCUR. While the concept of ARP has been previously argued and demonstrated via case studies, the validation of the model has proved circumstantial until now. This paper aims to empirically test and quantify the reliability of ARP forecasts via triangulation and correlation, and thereby make a significant new contribution to knowledge by determining the confidence level of the existing ARP model for the first time.

\section{Background}

Buildings are major assets and form a significant part of facility management operations. Although buildings are long lasting they require continual maintenance and restoration. Eventually, buildings 
can become inappropriate for their original purpose due to obsolescence, or can become redundant due to change in demand for their service. It is at these times that change is likely: demolition to make way for new construction, or some form of refurbishment or reuse (Langston and LaugeKristensen, 2002).

Refurbishment can of itself take many forms, ranging from simple redecoration to major retrofit or reconstruction. Sometimes the buildings are in good condition but the services and technology within them are outdated, in which case a retrofit process may be undertaken. If a particular function is no longer relevant or desired, buildings may be converted to a new purpose altogether. This is adaptive reuse.

Adaptive reuse is a special form of refurbishment that poses quite difficult challenges for designers. Changing the class (functional classification) of a building introduces new regulatory conditions and perhaps requires zoning consent. There are clear economic, environmental and social benefits that can make this option attractive to developers. In some cases increases in floor space ratios can be obtained and concessions received for pursuing government policy directions by regenerating derelict public assets. In recent years redundant city office buildings have been converted into high quality residential apartments, bringing people back to cities and in the process revitalizing them.

Adaptive reuse has been successfully applied in many types of facilities, including defence estates (e.g. Doak, 1999; Van Driesche and Lane, 2002), airfields (e.g. Gallent et al., 2000), government buildings (e.g. Abbotts et al., 2003), and industrial buildings (e.g. Ball, 1999; Anon., 2006). Around the world, adaptive reuse of historic buildings is seen as fundamental to sound government policy and sustainable development - e.g. in Atlanta, US (Newman, 2001), Canada (Brandt, 2006), Hong Kong (Poon, 2001), North Africa (Leone, 2003) and Australia (Maggs, 1999; McLaren, 1996).

Adaptive reuse can be quite dramatic. For example, conversion of disused industrial factories into shopping centres or churches into restaurants is possible. Property managers should be conscious of adaptive reuse solutions to redundant space and continually think about more productive uses for existing premises. It is therefore critical that we have mechanisms in place to ensure that when buildings are created they represent value to society as their long-term stakeholder, rather than their short-term custodians or brokers. Unmasking the social 'costs' of renewal can provide strong incentives for a transition to more sustainable energy use, less profligate use of new materials, and greater service from constructed building stock.

The ARP model developed by Langston et al. (2008) identifies and ranks adaptive reuse potential in existing buildings, and therefore can be described as an intervention strategy to ensure that collective social value is optimized and future redundancy is planned. The model has generic application to all countries and all building typologies. It requires an estimate of the expected physical life of the building (a worksheet has been developed to assist with estimation) and the current age of the building, both reported in years. It also requires an assessment of physical, economic, functional, technological, social, legal and political obsolescence, which is undertaken using surrogate estimation techniques as no direct market evidence exists.

Obsolescence is advanced as a suitable concept to objectively reduce the expected physical life of a building to its expected useful life. A discounting philosophy is adopted, whereby the annual obsolescence rate across all criteria is the 'discount rate' that performs this transformation. An 
algorithm based on a standard decay (negative exponential) curve produces an index of reuse potential (known as the ARP score) and is expressed as a percentage. Existing buildings in an organization's portfolio, or existing buildings across a city or territory, can therefore be ranked according to the potential they offer for adaptive reuse at any point in time. The decay curve can be reset by strategic capital investment during a renewal process by the current owner, or a future developer, at key intervals during a building's life cycle.

ARP scores in excess of $50 \%$ have high adaptive reuse potential, scores between $20 \%$ and $50 \%$ have moderate potential, and scores below $20 \%$ have low value, representing about one-third of the area under the decay curve in each case. Potential means that there is a propensity for projects to realize economic, social and environmental benefits when adaptive reuse is implemented. ARP is conceptualized as rising from zero to its maximum score at the point of its useful life, and then falling back to zero as it approaches physical life. Where the current building age is close to and less than the useful life, the model identifies that planning activities should commence.

The ARP model is summarized in Figure I. Its application was first demonstrated for a real case study in Hong Kong in Langston and Shen (2007). To date, however, the reliability of the ARP model has not been quantified in a robust manner.

Insert Figure I here ...

The shape of the 'mountain' depicting the rise of fall of adaptive reuse potential is a function of the obsolescence factors that are deemed to apply. Rather than envisage these as accurate estimates, they are more appropriately understood as ranges within which reasonable estimates occur. High rates of obsolescence mean lower useful lives and ARP profiles skewed towards the short term, while low rates of obsolescence mean higher useful lives and ARP profiles skewed towards the long term. The problem with the latter is that ARP scores are lower as the point of optimal intervention is delayed and leaves relatively little time to enjoy the benefits of the new purpose before the end of the facility's life cycle. Strategically, projects with the highest potential for adaptive reuse are those that have the greatest rate of premature obsolescence and ARP profiles skewed left.

\section{Adaptive Management}

Climate change presents significant challenges to society (e.g. Stern, 2006; Bouwer and Aerts, 2006). Many have concluded that climate change is the most important problem facing humankind, and indeed other life on Earth. The construction industry, which contributes $5-10 \%$ of national GDP globally, has a prominent role to play in meeting this challenge given that the built environment demands $40-50 \%$ of global resources and generates a proportional amount of waste (Langston and Ding, 2001). Climate change adaptation is about human response to this challenge, thus mitigating the impacts of a changing climate (Burton et al., 2005).

A major contribution that the construction industry can still make is ensuring that decisions about built assets are balanced: feasible, in the national interest and as sustainable as possible. A multiple criteria decision analysis (MCDA) framework is normally advocated (e.g. Mendoza and Martins, 2006; Herath and Prato, 2006). There is a need amongst the built environment professions for a transparent understanding of the goals of multiple stakeholders that underpin optimal decisions. 
Further, given the uncertainty associated with these choices, there is a need to refine predictions by learning from experience so to improve future decision heuristics.

Adaptive management (AM) is a powerful approach to reducing ecological uncertainty and improving the overall performance of many resource-based systems (Gregory et al., 2006). It has the potential to improve the expected net benefit of specific developmental initiatives. It is sometimes described as "learning by doing". Recently Linkov et al. (2006) suggested that AM be combined with MCDA to provide structured, clear decisions and allow for refinement of criteria goals and weightings based on feedback regarding actual project performance. Accelerated learning from experience assures that better decisions are made in the future.

Belton and Stewart (2002) define MCDA as an umbrella term for a collection of formal approaches for group or individual decision-making that take explicit account of multiple criteria. MCDA has been one of the most widely applied decision models for sustainable development, in areas like land use planning (e.g. Stewart et al., 2004), forest management (e.g. Laukkanen et al., 2004), wetland protection (e.g. Herath, 2004), wildlife management (e.g. Berbel and Zamora, 1995), mining (e.g. Martin et al., 1996), transportation (e.g. Mergias et al., 2007), portfolio management (e.g. Subbu et al., 2007), fisheries (e.g. Mardle and Pascoe, 2002), and built environment assets (e.g. Kaklauskas et al., 2005).

Not surprisingly, MCDA has been applied to mainstream construction and property problems, such as selecting appropriate refurbishment opportunities as discussed in this paper, as well as wider design and asset management applications. Different refurbishment applications are reported, ranging from simple decision models (e.g. Kincaid, 2002) to complex ones (e.g. Bostenaru Dan, 2004). There appears to be no clear consensus or agreement on the identification of key criteria, attributes and weighting. Indeed, these are likely to be dependent on the particular context, and at least for weightings, different in each case. Sun et al. (2008) concede that despite rising attention on asset management decision-making in recent years, there are few practical publications in this area. Value management is well accepted in the built environment and is a particular instance of MCDA, yet other evidence of acceptance or implementation of MCDA tools in practice is virtually non-existent.

Langston developed an MCDA tool for built assets (known as SINDEX) that guides decision makers to consider four criteria: (1) maximize wealth, (2) maximize utility, (3) minimize resources, and (4) minimize impact (Langston, 2003; Ding and Langston, 2004). This tool has been applied to life cycle decisions for built assets and has been recommended to replace traditional net present value methodologies that have been used routinely for over 150 years (Langston, 2005). SINDEX calculates a "sustainability index" that balances these criteria and is an important and contemporary milestone towards a more comprehensive MCDA tool. What this previous work lacked was a credible link between expectation and actuality.

AM acts as an opportunity for continuous process improvement for MCDA. It is a structured, iterative process of optimal decision-making in the face of uncertainty, which aims to reduce uncertainty over time via system monitoring and learning. In this way, decision making simultaneously maximizes one or more resource objectives and, either passively or actively, accrues information needed to improve future management. One of the most successful applications of AM has been in the area of waterfowl harvest management in North America, most notably for the mallard (Johnson et al., 1993; Nichols et al., 2007). 
Linkov et al. (2006:1087) advocate a merge of MCDA and AM. They believe "that a combination of adaptive management and MCDA will provide a powerful framework for a wide range of environmental management problems". Figure II suggests how this might be done. MCDA processes are shown on the left side of diagram, while AM processes are shown on the right. This combined approach has never been applied outside of a natural resource management context. Yet the built environment is an ideal test bed for this application. Multiple criteria and weightings are seldom reviewed, and so decisions that are taken (for better or for worse) do not systematically inform decisions on future developmental initiatives, and so not only is there no agreed "model" for evaluation, but the range of approaches are likely to remain sub-optimal since we are not collectively learning from our past 'experiments'. This clearly must change.

Insert Figure II here ...

Passive AM begins by using predictive modeling based on present knowledge to inform management decisions. As new knowledge is gained, the models are updated with additional criteria and refined weights, and management decisions adapted accordingly. On the other hand, active AM involves intentionally experimenting with management strategies in order to test hypotheses about the way the system works. Such active experimentation further accelerates learning and is more likely than passive AM to lead to optimal decisions in the future.

When evaluating projects and facilities it is important to take a holistic view. Current practice, however, is primarily concerned with issues of profitability and the financial bottom line. This approach leads to decisions that are not necessarily compatible with wider social considerations and sustainable development goals. A new methodology is needed. John Elkington proposed the triple bottom line concept in 1997. This approach demands consideration of financial, social and environmental parameters (known as the 3Ps of profit, people and places). It is an approach that is receiving widespread international recognition. Such methodologies are examples of MCDA. Using recognized techniques, various criteria can be measured and assembled into a single decision model. In this way it is possible to compare alternatives to determine best value, and to benchmark projects and facilities against established performance targets.

\section{4. $\quad$ Method}

This study represents the culmination of work from an Australian Research Council Linkage Project (2007-2010), involving a partnership between Bond University, Deakin University, Williams Boag Architects (WBa) and The Uniting Church in Australia (UCA). As part of this study a large number of case studies of religious buildings (churches, manses, community halls and auxiliary facilities) were analyzed.

A case study methodology was chosen as it is commonly used in an empirical study involving processes, activities and events (Creswell, 2003). This is appropriate here as this research involves archival data and concerns future decision-making where:

1) the researcher has limited control over events,

2) 'how' or 'why' questions are being asked, and

3) the focus of the research is on contemporary phenomenon within a real-life context (Yin, 2009). 
The researchers had access to projects from across Victoria (Australia), which were over 400 in number. Fifty projects were considered sufficient to draw valid conclusions, and were largely identified by WBa and UCA to represent a diverse mix of building type, age, location and congregational context. From the perspective of the researchers, the selection of the case studies was effectively random. They comprise existing assets typical of the UCA's total property portfolio, and are not necessarily earmarked for refurbishment or capable of successful adaptive reuse. Using information contained in UCA files, each case study was assessed in order to determine its ARP score. A ranked list of these projects (in decreasing order) is shown in Table I.

Insert Table I here ...

The method used to calculate the ARP scores contained in the master list is known as the integrated model (Langston, 2008). It is computed via an Excel spreadsheet, based on inputs of physical life, date of construction or last major refurbishment, and seven obsolescence scores (physical, economic, functional, technological, social, legal and political). An example of the spreadsheet template for one of the case studies (Bendigo) is provided in Figure III.

Insert Figure III here ...

The date of construction (or last major refurbishment) was always recorded in the UCA's property database. Obsolescence scores, however, were not recorded. The rationale for assessing obsolescence has been described in detail in Langston (2011), and is summarized below:

1) Physical obsolescence: examination of maintenance policy and performance, specifically the annual budget allocation for routine maintenance and repair

2) Economic obsolescence: geographic location of a building relative to a major city, central business district or other primary market or business hub

3) Functional obsolescence: extent of flexibility embedded in a building's design, as evidenced by annual churn costs

4) Technological obsolescence: building's reliance on high levels of energy in order to provide occupant comfort

5) Social obsolescence: relationship between building function and its marketplace, such as reliance on external income, or trends in demand or relevance of service

6) Legal obsolescence: quality or standard of the original design, as evidenced by its initial cost per $\mathrm{m}^{2}$

7) Political obsolescence: level of public and local community interest surrounding a project

Each factor is assessed on a scale of 0 to 20 , where 0 indicates no negative influence and 20 indicates significant negative influence, using interim scores of 5, 10 and 15 as appropriate. In the case of the political factor, positive support through planning incentives can lead to a score between -20 (favourable) and +20 (unfavourable), where a zero score is described as apathy. To explain further, a generous annual maintenance budget would indicate that the building is being well looked after, and hence the physical obsolescence factor would be set at zero. If little attention to maintenance was evidenced or expected, then the physical obsolescence factor would be set at 20. Using the same approach, a building sited in the central business district of a major urban centre, an open plan or flexible floor plan, a green building, an owner-occupied building with strong market connections, a high quality building, and a site with an absence of heritage or planning controls/restrictions in place 
would each score well (obsolescence factor $=0$ ). It should be noted that environmental obsolescence is subsumed into technological, social, legal and political factors and therefore is not measured separately. Group consensus was used to agree final scores.

From this list of 50 case studies a smaller number were selected for detailed examination in the field, including inspection and discussions with members of the presiding congregation. The intention was to pick projects that were evenly spaced throughout the list in terms of their ARP score so that a clear and unchallenged ranking of merit could be formed. The highest ARP score was $73.4 \%$ (Mildura) and the lowest ARP score was $0.0 \%$ (Rutherglen). Ten further projects were selected between these two extremes, making twelve case studies in all. Case studies that are the subject of more detailed investigation in the next stage of the study are shown as shaded rows in the earlier Table I.

The twelve case studies were therefore a 'distillation' of the 400+ projects owned by the UCA designed to ensure a suitable demographic mix (building type, age, location and congregational context) and an even spread of ARP score. Case studies were divided equally between worship centres, community halls and manses. Five case studies were in suburban Melbourne, two were in major regional centres, three were in rural Victoria and two were in remote locations. One case study was heritage-listed. The average age of the case studies was 64 years (compared to 75 years for the full 50 properties), ranging from 4 to 153 years old (reflecting the extremities of the full list).

The ARP scores and relative ranking formed the basis for comparison using iconCUR. iconCUR is a decision-making model that combines AM and MCDA methodologies in the built environment discipline for the first time. Case studies were assessed using the key parameters of condition (C), utilization $(U)$ and reward (R). The latter included multiple stakeholder interest. These parameters were mapped as $x, y$ and $z$ coordinates in three-dimensional space. In a two-dimensional format, each case study could be categorized according to which direction for future property management would be the most appropriate. An example of the spreadsheet template for one of the case studies (again, Bendigo) is provided in Figure IV.

Insert Figure IV here ...

Using key variables of condition (measured on a scale of 0-5) and utilization (similarly measured on a scale of 0-5), projects can be mapped to determine the most likely strategies for their ongoing care. Essentially spatial coordinates can be calculated to determine relative positioning, and this can be assessed as traceable trends over a number of years. It also includes a third dimension of reward (scale 0-5) to account for the significance of decisions using a triple bottom line approach in the context of multiple stakeholder interests. A 3D matrix (cubic) is thus created where the coordinates of properties can be compared to optimum decisions reflected by each of the matrix corners.

Reward is determined as the combination of collective utility, based on a triple bottom line (TBL) philosophy, and stakeholder interest. The value for 'asset performance' represents the combination of condition ( $x$ axis), utilization ( $y$ axis) and reward ( $z$ axis). In both cases these values are on a scale of 0 (poor) to 5 (excellent).

Owners would like to move as many of their properties as possible into the upper right-hand corner of the matrix, so adaptive reuse, renovation and reconstruction are potential strategies to get there. Clearly these types of decisions are different to those that would apply to new (greenfield) 
developments, which are assumed to be automatically assigned to the upper right-hand corner upon handover, but track slowly towards the lower left-hand corner as they age. Properties move up the sloping plane between these corners as capital is invested, and move down due to the effects of natural decay. So a tidal trend is established over time as the tension between deterioration of physical condition and lower levels of property utilization is evidenced by property management strategies and interventions to improve performance. The process of learning how to make better decisions over time, and feeding back new knowledge to the model, is the essence of AM (Langston and Smith, 2010).

\section{Results}

Figure $V$ shows the position of all twelve case studies using the two-dimensional base of the iconCUR model. Warrnambool, Hawthorn and Brunswick were closest to a retain/extend outcome. Both Heidelberg case studies were closest to a renovate/preserve outcome. Rutherglen and Keilor were more likely to lead to a reconstruct/dispose outcome. The remainder of case studies was more suitable for reuse/adapt outcomes.

Insert Figure $V$ here ...

The distance between each case study coordinate in three-dimensional space and the upper adaptive reuse corner (representing maximum reward, i.e. $x=5, y=0, z=5$ ) is used to determine a ranking for adaptive reuse potential. This approach is completely different to that of the ARP model and thus can be used to validate it objectively.

Using this approach it was evidenced that properties with high ARP scores were also aligned to adaptive reuse decisions, depicted as having high condition, low utilization and high reward. A strong correlation was found between ARP scores and the distance from case study coordinates to the maximum adaptive reuse corner. Table II summarizes the key results. The rank order of case studies according to the agreed consensus of the research team (8 people) is also included, and used to sort the overall rank in descending order of adaptive reuse potential.

Insert Table II here ...

Figures VI and VII test for the extent of correlation between iconCUR and ARP using scores and ranks respectively. Values for $R^{2}$ around 0.7 or higher are normally expected to represent strong correlation. The $\mathrm{R}^{2}$ based on score is 0.76 and the $\mathrm{R}^{2}$ based on rank is 0.83 . Using this approach, comprising two completely different pathways to assessing adaptive reuse potential, both methods are shown to be reliable. Thus it is concluded that either method could be used to assess properties to determine where design efforts targeted towards adaptive reuse should be concentrated.

Insert Figures VI and VII here ...

No attempt was made to exclude outliers given that the number of data points in the analysis was limited. The $\mathrm{R}^{2}$ values obtained indicate the degree of agreement between the two approaches rather than comment on dependency. There is no dependency.

These results were also compared against research team expertise. Opinions on rankings were agreed in a workshop context before ARP and iconCUR scores were revealed to the participants. 
Research team members possessed a range of expertise and case study knowledge and had good understanding of adaptive reuse concepts and strategies. Once again, strong correlations were discovered. The $R^{2}$ based on ARP versus expert opinion is 0.69 and the $R^{2}$ based on iconCUR versus expert opinion is 0.76 . Both models therefore reflect the expert opinions. Figures VIII and IX present the correlation charts.

Insert Figures VIII and IX here ...

These results use a form of triangulation to validate the ARP model's ability to identify adaptive reuse intervention. Case studies could also be assessed in terms of their current triple bottom line reward in the context of the current asset value (using iconCUR). High ARP scores with low current reward represent TBL opportunity. Maffra is a good example. Case studies already with high current reward would not have much scope for reward improvement. Warrnambool scores 2.86 out of 5 but nevertheless displays the highest reward in the list. Table III sorts the key results by reward.

Insert Table III here ...

\section{Discussion}

The correlation results can be criticized, as there are only twelve data points involved. Commonly thirty data points are seen as leading to a confident conclusion. Adjusted $R^{2}$ is an alternative approach that proportionally takes into account a smaller number of data points. In all four correlations, the adjusted $R^{2}$ is nearly identical $(0.74,0.81,0.66$ and 0.74 respectively), giving strength to the conclusions that have been drawn.

It is also a possible criticism that the method used in this study has merely demonstrated that both models are consistent, not necessarily that both are right. It is for this reason that expert opinion was also introduced. The likelihood that all three are consistently wrong is very low. Given none of the case studies have actually been adaptively reused, it is not yet possible to compare forecast potential with reality.

Some subjectivity exists with both models. In the case of ARP, the assessment of the seven obsolescence factors comprises a degree of uncertainty. However, the twelve case studies that were selected all had low risk levels on ARP score accuracy, and hence variations in assessment would not have greatly changed the scores, and definitely not the ranks. In the case of iconCUR, all of the individual ratings for each of condition, utilization, collective utility and stakeholder interest are subjective, as are the weightings used in the matrix. To reduce bias, all weightings were kept constant for all calculations, and so would not have much influence in manipulating the outcomes. Stakeholder interest was considered common to all case studies and therefore did not play any part in differentiating scores.

It must nevertheless be noted that ARP and iconCUR are both forecasting models, and by definition need to predict the future. This is an art rather than a science, and requires judgement and experience. Subjectivity pervades all aspects of the process, yet as can be seen above, the expected variability in this study has been limited as much as possible. The research relied on group consensus in all aspects of the analysis, which is reflective of what is expected to occur when the models are applied in the field by industry. Such consensus involved discussion and decision when differences in opinion became manifest. 
Overall, a high level of confidence is held in the calculation of scores and ranks. Only further testing on many more case studies can increase confidence. So at this stage the results can be considered as preliminary, yet very encouraging. It is not expected that the two models will always agree, but the values for $\mathrm{R}^{2}$ found in this study give a guide to the level of reliability that might be expected.

\section{Conclusion}

The use of the ARP model to quickly rank and prioritize properties within a client portfolio is attractive. More detailed design work, which is time consuming and expensive, would be focused only on those projects where the potential for a successful outcome is high. It is recommended that ARP be undertaken first, and those projects with ARP scores in excess of $50 \%$ that reveal proximity to the optimum point of intervention be carried forward to a second level of evaluation using iconCUR. Where consensus is found indicating adaptive reuse is the correct strategy, then more detailed investigations and plans may follow. Such an approach will improve efficiency and confidence.

This paper demonstrates that the reliability of the ARP model can indeed be quantified, and for the first time validates an approach that previously was merely an 'illustrated concept'. Through the use of a triangulated approach (comprising ARP, iconCUR and expert opinion) to assess the relative ranks of twelve diverse case studies, consistency is shown and the level of confidence in the correct identification of adaptive reuse opportunities is at least $70 \%$. Confidence is increased further by applying ARP and iconCUR models in sequence. Over time it is expected that the principles of adaptive management (learning by doing) will enable these models to be systematically improved.

The methodology used for ARP validation is limited to one building classification (religious buildings) in one geographic area (Victoria, Australia). Further evidence is needed to determine if these findings are replicable for a wider range of contexts. Research is also ongoing to determine a star rating system for new building design to assess and maximize its potential for future adaptive reuse intervention.

\section{Acknowledgements}

The financial support of the Australian Research Council underpinning this research is gratefully acknowledged.

\section{References}

Abbotts, J., Ertell, K.B., Leschine, T.M. and Takaro, T.K. (2003) Building Leasing at the Department of Energy's Hanford Site: Lessons Learned from Commercial Reuse, Federal Facilities Environmental Journal, Spring, pp.95-107.

Anon., (2006) Sustainable Solar Solutions Case Study 02, Sustainability Victoria, Melbourne, 3, URL: http://www.sustainability.vic.gov.au/www/html/1589-case-studies.asp.

Ball, R. (1999) Developers, Regeneration and Sustainability Issues in the Reuse of Vacant Industrial Buildings, Building Research and Information, vol.27, no.3, pp.140-148.

Belton, V. and Stewart, T.J. (2002) Multiple Criteria Decision Analysis: An Integrated Approach, Kluwer Academic Publishing. 
Berbel, J. and Zamora, R. (1995) An Application of MOP and GP to Wildlife Management (Deer), Journal of Environmental Management, vol.44, no.1, pp.29-38.

Bostenaru Dan, M.D. (2004) Multi-criteria Decision Model for Retrofitting Existing Buildings, Natural Hazards and Earth System Sciences, vol.4, pp.485-499.

Bouwer L.M. and Aerts J.C.J.H. (2006) Financing Climate Change Adaptation, Disasters, vol.30, no.1, pp.49-63.

Brandt, M. (2006) How to Adaptively Reuse a Community Asset? Heritage: the magazine of the Heritage Canada Foundation, vol.9, no.2, pp.21-22.

Burton I., Malone E.L. and Huq S. (2005) Adaptation Policy Frameworks for Climate Change:

Developing Strategies, Policies and Measures, Cambridge University Press.

Chusid, M. (1993) Once is Never Enough, Building Renovation, Mar-Apr, pp.7-20.

Creswell, J.W. (2003) Research Design: Qualitative, Quantitative and Mixed Methods Approaches, Sage Publications Inc.

Ding, G. and Langston, C. (2004) Multiple Criteria Sustainability Modelling: Case Study on School Buildings, The International Journal of Construction Management, vol.4, no.2, pp.13-26.

Doak, J. (1999) Planning for the Reuse of Redundant Defense Estate: Disposal Processes, Policy Frameworks and Development Impacts, Planning Practice and Research, vol.14, no.2, pp.211-224.

Douglas, J. (2006) Building Adaptation (Second Edition), Butterworth-Heinemann.

Gallent, N., Howet, J. and Bellt, P. (2000) New Uses for England's Old Airfields, Area, vol.32, no.4, pp.383-394.

Gregory, R., Failing, L. and Higgins, P. (2006) Adaptive Management and Environmental Decision Making: A Case Study Application to Water Use Planning, Ecological Economics, vol.58, no.2, pp.434447.

Herath G. and Prato T. (2006) Using Multi-criteria Decision Analysis in Natural Resource Management, Ashgate Publishing.

Herath, G. (2004) Incorporating Community Objectives in Improved Wetland Management: The Use of Analytic Hierarchy Process, Journal of Environmental Management, vol.70, no.3, pp.263-273.

Johnson, F.A., Williams, B.K., Nichols, J.D., Hines, J.E., Kendall, W.L., Smith, G.W. and Caithamer, D.F. (1993) Developing an Adaptive Management Strategy for Harvesting Waterfowl in North America, in Transactions of the North American Wildlife Natural Resources Conference, pp.565-583.

Kaklauskas, A., Zavadskas, E.K. and Raslanas, S. (2005) Multivariant Design and Multiple Criteria Analysis of Building Refurbishments, Energy and Buildings, vol.37, no.4, pp.361-372.

Kincaid, D. (2002) Adapting Buildings for Changing Uses: Guidelines for Change of Use Refurbishment, Spon Press. 
Langston, C. (2003) Multiple Criteria Sustainability Modelling, in proceedings of AUBEA 2003:

Working Together, Langston, C. (ed.), Geelong, 9-11 July, pp.267-274.

Langston, C. (2005) Life-cost approach to building evaluation, Elsevier.

Langston, C. (2008) The Sustainability Implications of Building Adaptive Reuse (keynote paper), in proceedings of CRIOCM2008, Beijing, Oct/Nov, pp.1-10.

Langston, C. (2011) Estimating the Useful Life of Buildings, in proceedings of AUBEA2011 Conference, April, Gold Coast, Australia (accepted).

Langston, C. and Ding, G. (2001) Sustainable Practices in the Built Environment (second edition), Butterworth-Heinemann.

Langston, C. and Lauge-Kristensen, R. (2002) Strategic Management of Built Facilities, ButterworthHeinemann.

Langston, C. and Shen, L.Y. (2007) Application of the Adaptive Reuse Potential Model in Hong Kong: A Case Study of Lui Seng Chun', The International Journal of Strategic Property Management, vol.11, no.4, pp.193-207.

Langston, C. and Smith, J. (2010) Making Better Decisions about Built Assets, in proceedings of Building a Better World CIB 2010 World Congress, Salford, 10-13 May.

Langston, C., Wong, F., Hui, E and Shen L.Y. (2008) Strategic Assessment of Building Adaptive Reuse Opportunities in Hong Kong, Building and Environment, vol.43, no.10, pp.1709-1718.

Laukkanen, S., Palander, T. and Kangas, J. (2004) Applying Voting Theory in Participatory Decision Support for Sustainable Timber Harvesting, Canadian Journal of Forest Research, vol.34, no.7, pp.1511-1524.

Leone, A. (2003) Late Antique North Africa: Production and Changing Use of Buildings in Urban Areas, Al-Masáq, vol.15, no.1, pp.21-33.

Linkov, I., Satterstrom, F.K., Kiker, G., Batchelor, C., Bridges, T. and Ferguson, E. (2006) From Comparative Risk Assessment to Multi-criteria Decision Analysis and Adaptive Management: Recent Developments and Applications, Environment International, vol.32, no.8, pp.1072-1093.

Maggs, A. (1999) Adaptive Reuse, Place, vol.1, no.4, pp.33-34.

Mardle, S.J. and Pascoe, S. (2002) Modelling the Effects of Trade-offs between Long and Short-term Objectives in Fisheries Management, Journal of Environmental Management, vol.65, no.1, pp.49-62.

Martin, W.E., Shields, D.J., Tolwinski, B. and Kent, B. (1996) An Application of Social Choice Theory to U.S.D.A. Forest Service Decision Making, Journal of Policy Modeling, vol.18, no.6, pp.603-621.

McLaren, P. (1996) Adaptation and Reuse, Monuments and Sites Australia: Australia ICOMOS, Sri Lanka National Committee of ICOMOS, pp.170-176. 
Mendoza, G.A. and Martins, H. (2006) Multi-criteria Decision Analysis in Natural Resource Management: A Critical Review of Methods and New Modelling Paradigms, Forest Ecology and Management, vol.230, no.1-3, pp.1- 22.

Mergias, I., Moustakas, K., Papadopoulos, A. and Loizidou, M. (2007) Multi-criteria Decision Aid Approach for the Selection of the Best Compromise Management Scheme for ELVs: The Case of Cyprus, Journal of Hazardous Materials, vol.147, no.3, pp.706-717.

Newman, H.K. (2001) Historic Preservation Policy and Regime Politics in Atlanta, Journal of Urban Affairs, vol.23, no.1, pp.71-86.

Nichols, J.D., Runge, M.C., Johnson, F.A. and Williams, B.K. (2007) Adaptive Harvest Management of North America Waterfowl Populations: A Brief History and Future Prospects, Journal of Ornithology, vol.148, no.2, pp.343- 349.

Poon, B.H.S. (2001) Buildings Recycled: City Refurbished, Journal of Architectural Education, vol.54, no.3, pp.191-194.

Stern N. (2006) Stern Review on the Economics of Climate Change, HM Treasury.

Stewart, T.J., Janssen, R. and Van Herwijnen, M. (2004) A Genetic Algorithm Approach to Multiobjective Land Use Planning, Computers and Operations Research, vol.31, no.14, pp.2293-2313.

Subbu, R., Russo, G., Chalermkraivuth, K. and Celaya, J. (2007) Multi-criteria Set Partitioning for Portfolio Management: A Visual Interactive Model, in proceedings of Computational Intelligence in Multicriteria Decision Making Conference, Honolulu, 1-5 April, pp.166-171.

Sun, Y., Fidge, C. and Ma, L. (2008) A Generic Split Process Model for Asset Management Decisionmaking, URL: http://sky.fit.qut.edu.au/ fidgec/Publications/sun08a.pdf.

Van Driesche, J. and Lane, M. (2002) Conservation through Conversation: Collaborative Planning for Reuse of a Former Military Property in Sauk County, Wisconsin, Planning Theory and Practice, vol.3, no.2, pp.133-153.

Yin, R.K. (2009) Case Study Research Design and Methods, Sage Publications Inc. 


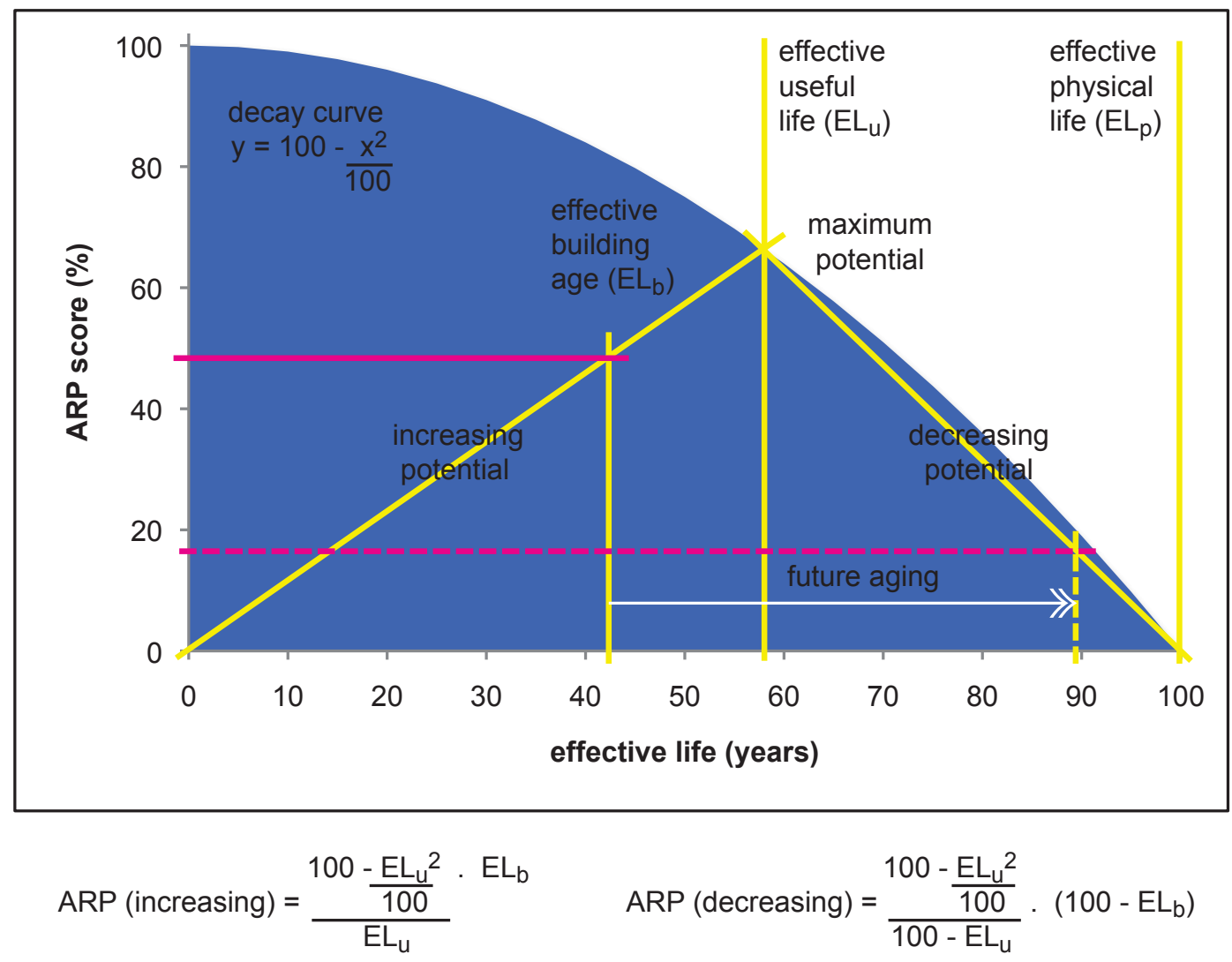

Figure I: Adaptive reuse potential model (Langston, 2008) 
Table I: ARP scores for 50 UCA case studies in Victoria

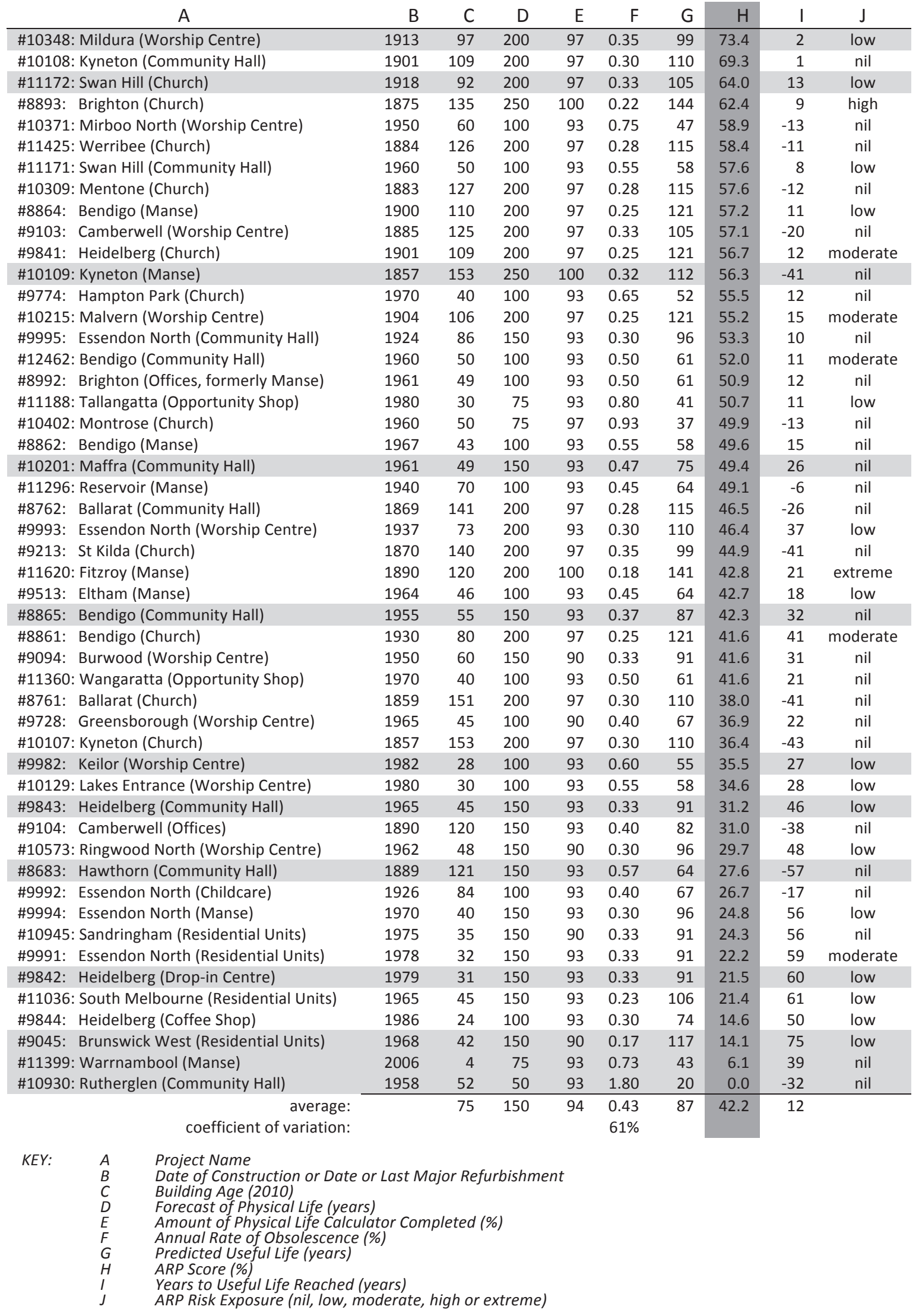




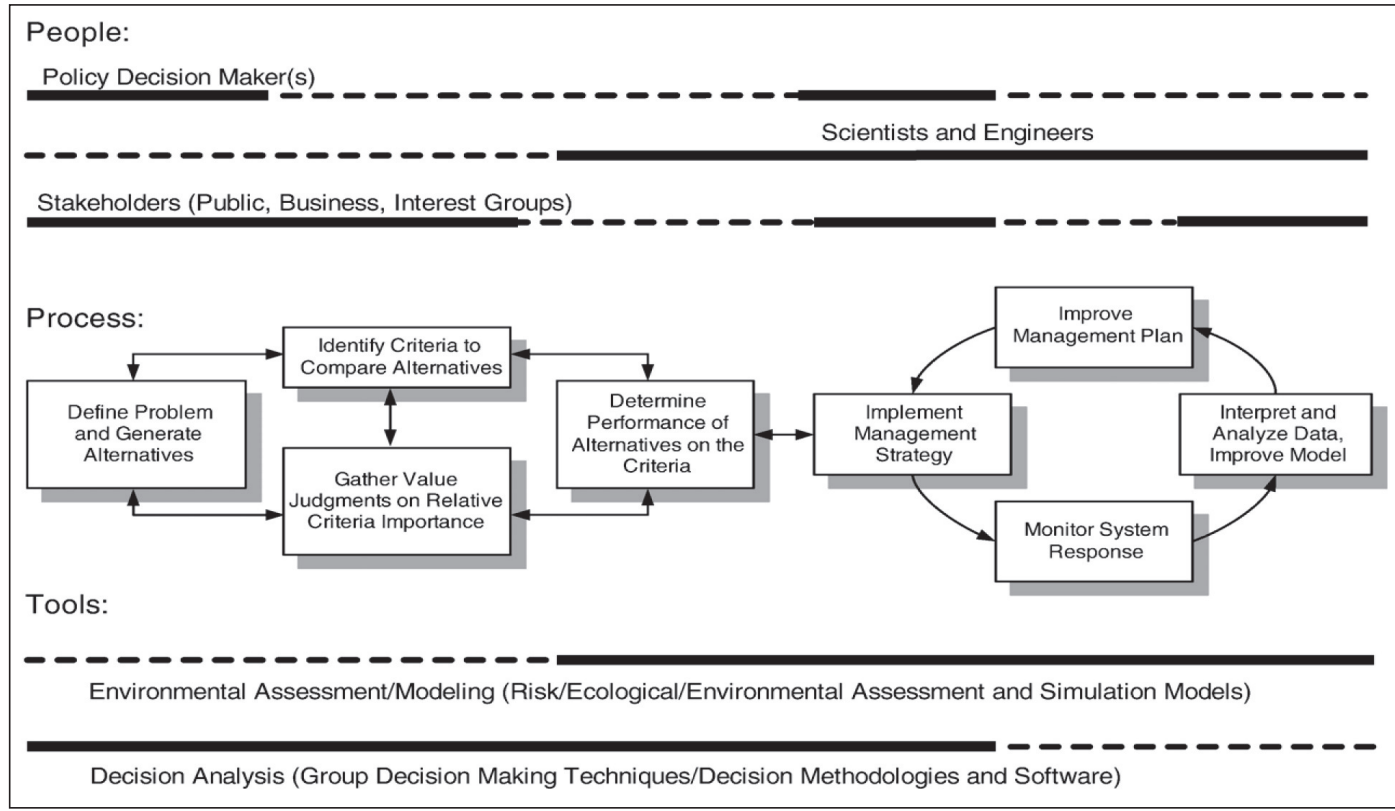

Figure II: A conceptual framework for sustainable decisions (Linkov et al., 2006:1088) 


\section{Physical life worksheet}

\#8865: 24 Myers Street Bendigo: Community Hall

Single storey brick and block structure with metal deck roof on steel portal

frame. Stage and amenities. Adjoining site contains a church, two manses an

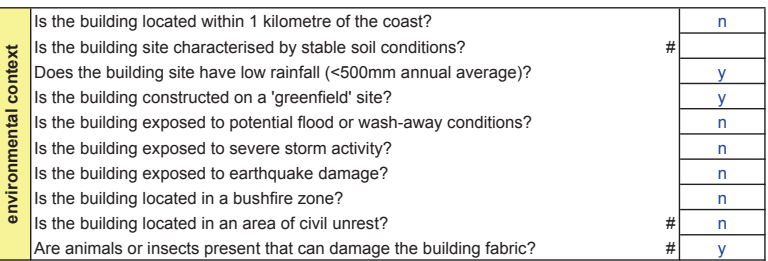

Are animals or insects present that can damage the building fabric?

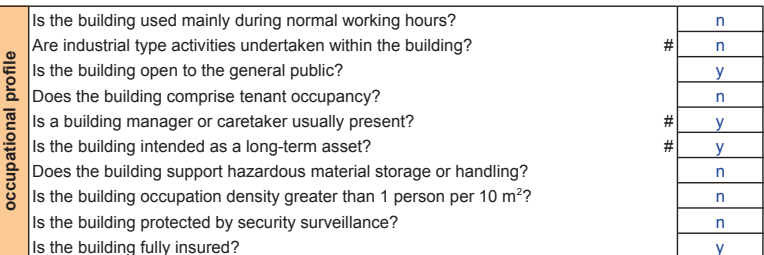

Is the building design typified by elements of massive construction? Is the main structure of the building significantly over designed?

Is the building structure complex or unconventional?

Are building components intended to be highly durable?

Are there other structures immediately adjacent to the building?

Does the building have a stable footing system?

Was the workmanship standard for the project high?

Is the building properly weatherproofed from water entry?

Is the building protected against accidental fire events?

Is the building designed as a public monument or landmark?

Notes:

Questions indicated (\#) are double weighted

Blank responses are ignored

\section{Adaptive reuse potential}

adaptive reuse potential $(\mathrm{ARP} \%)=$

Well maintained, regional centre location, flexible space, moderate energy demand, strong congregation, average quality construction.

$\begin{array}{lrr}\text { physical life }\left(L_{p}\right)= & 150 \text { years } & \text { index }= \\ \text { building age }\left(L_{b}\right)= & 55 \text { years } & \text { override }=\end{array}$

160

today's date $=$

2010

original construction date $=, \quad 1955$

(enter only if refurbishment was major)

physical $\left(\mathrm{O}_{1}\right)$

economic $\left(\mathrm{O}_{2}\right)$

functional $\left(\mathrm{O}_{3}\right)$

technological $\left(\mathrm{O}_{4}\right)$

social $\left(\mathrm{O}_{5}\right)$

legal $\left(\mathrm{O}_{6}\right)$
political $\left(\mathrm{O}_{7}\right)$

0.05
0.10

political $\left(\mathrm{O}_{7}\right)$

total $=$

0.55

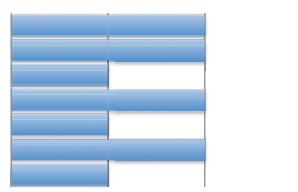

obsolescence rate $\mathrm{pa}=$

useful life $\left(L_{u}\right)=$

86.6 years adaptive reuse potential is moderate and increasing

years to useful life $=\quad 31.6$ years

maximum arp score $(\%)=\quad 66.6$

ARP difference $(\%)=$

$57.5 \%$

(assuming $L_{u}=L_{b}$ )

Risk Management:

best case obsolescence $=\quad 0.50$ (low)

useful life $\left(L_{u}\right)=$

$\mathrm{ARP} \%=$

91.

worst case obsolescence $=\quad 0.60$ (high

useful life $\left(L_{u}\right)=$

82.4
46.6

$\mathrm{ARP} \%=$

ARP difference $(\%)=$

22.1

Notes:

3\% completed Floor area $823 \mathrm{~m} 2$. adaptive reuse potential is moderate (no change) and increasing

adaptive reuse potential is moderate (no change) and increasing

Figure III: ARP spreadsheet template for Bendigo case study 


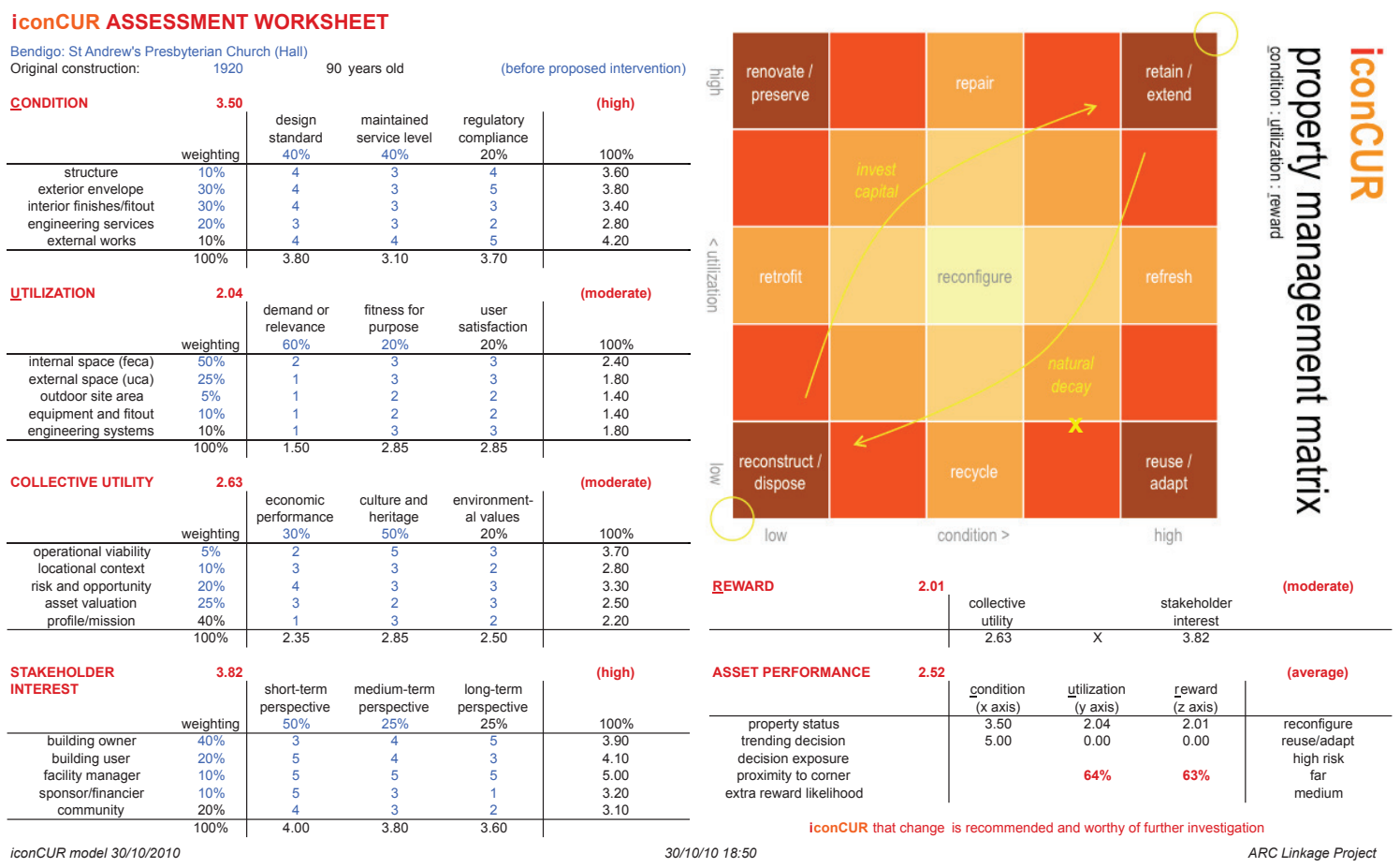

Figure IV: iconCUR spreadsheet template for Bendigo case study 


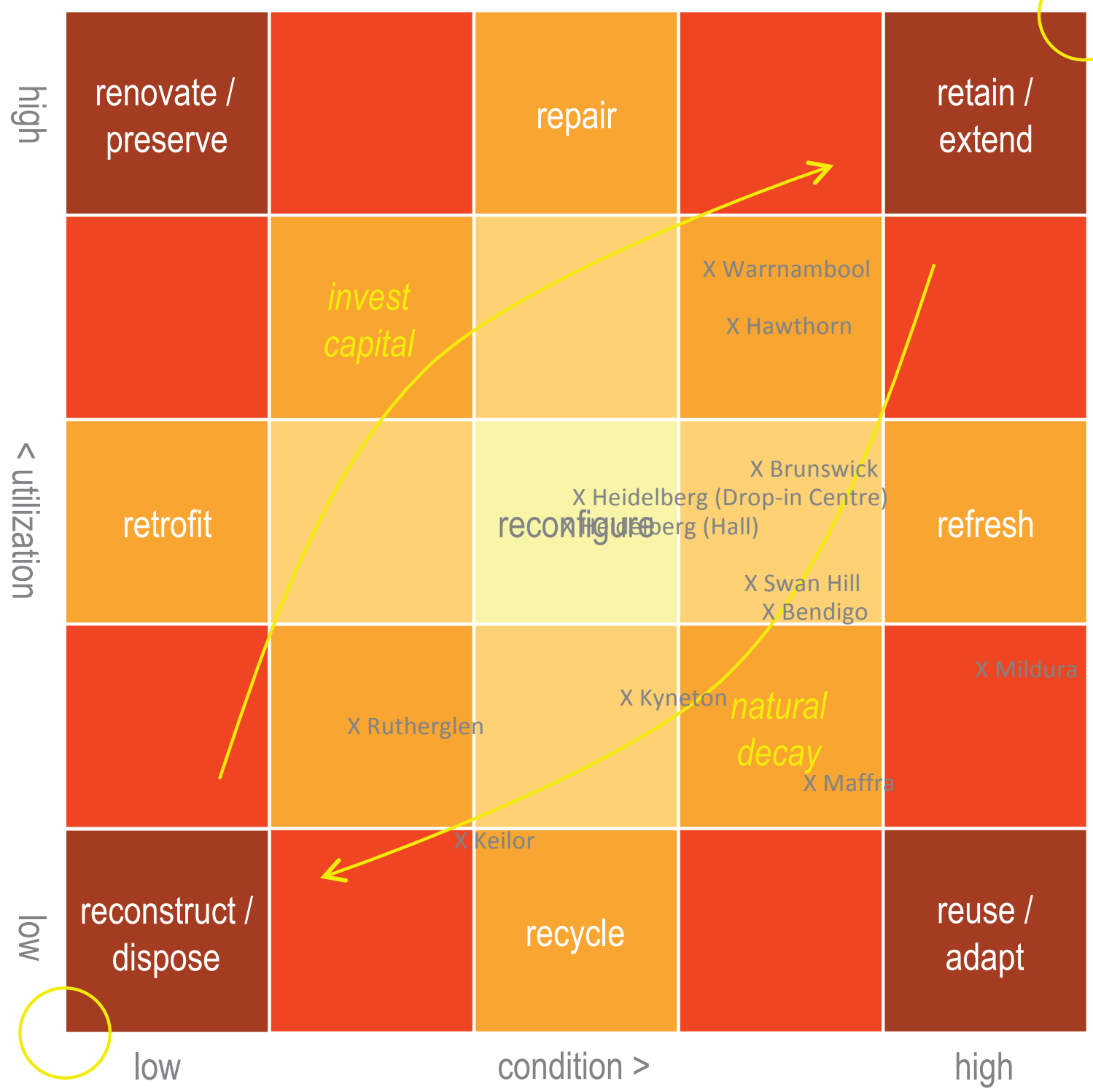

Figure V: iconCUR results plotted on two-dimensional plane (condition and utilization) 
Table II: Summary of results (sorted by expert opinion)

\begin{tabular}{|c|c|c|c|c|c|c|c|}
\hline \multirow{2}{*}{$\begin{array}{l}\text { Case Study } \\
\text { name }\end{array}$} & \multirow{2}{*}{$\begin{array}{c}\text { Outcome } \\
\text { trending decision }\end{array}$} & \multicolumn{3}{|c|}{ Modeling } & \multicolumn{3}{|c|}{ Rank } \\
\hline & & $i \operatorname{con} C U R^{*}$ & $A R P$ & reward & iconCUR & $A R P$ & team \\
\hline Maffra & reuse/adapt & 3.48 & 49.4 & 2.02 & 2 & 4 & 1 \\
\hline Mildura & reuse/adapt & 3.19 & 73.4 & 2.46 & 1 & 1 & 2 \\
\hline Kyneton & reuse/adapt & 3.90 & 56.3 & 2.27 & 4 & 3 & 3 \\
\hline Bendigo & reuse/adapt & 3.92 & 42.3 & 2.01 & 5 & 5 & 4 \\
\hline Swan Hill & reuse/adapt & 3.76 & 64.0 & 2.38 & 3 & 2 & 5 \\
\hline Heidelberg (hall) & renovate/preserve & 4.62 & 31.2 & 2.09 & 8 & 7 & 6 \\
\hline Heidelberg (drop-in centre) & renovate/preserve & 4.69 & 21.5 & 2.04 & 10 & 9 & 7 \\
\hline Brunswick & retain/extend & 4.14 & 14.1 & 2.49 & 6 & 10 & 8 \\
\hline Hawthorn & retain/extend & 4.66 & 27.6 & 2.58 & 9 & 8 & 9 \\
\hline Keilor & reconstruct/dispose & 4.55 & 35.5 & 1.86 & 7 & 6 & 10 \\
\hline Rutherglen & reconstruct/dispose & 5.39 & 0.0 & 1.55 & 12 & 12 & 11 \\
\hline Warrnambool & retain/extend & 4.76 & 6.1 & 2.86 & 11 & 11 & 12 \\
\hline
\end{tabular}




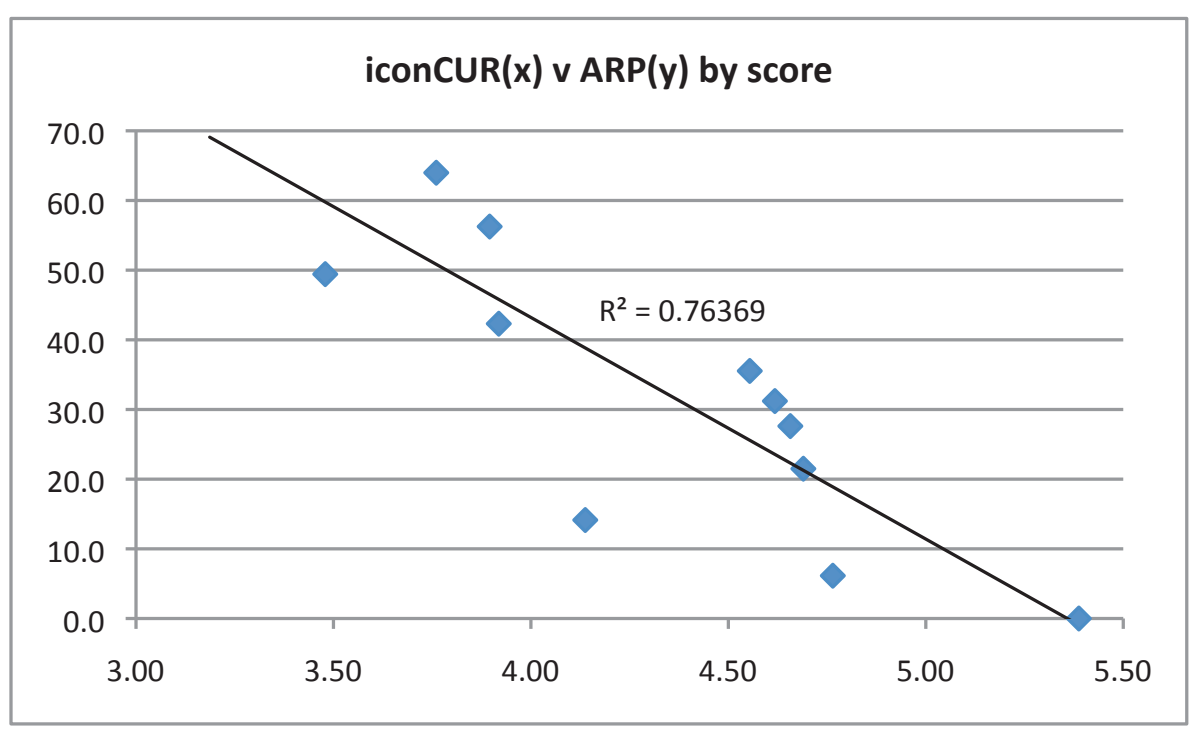

Figure VI: Correlation between iconCUR and ARP scores 


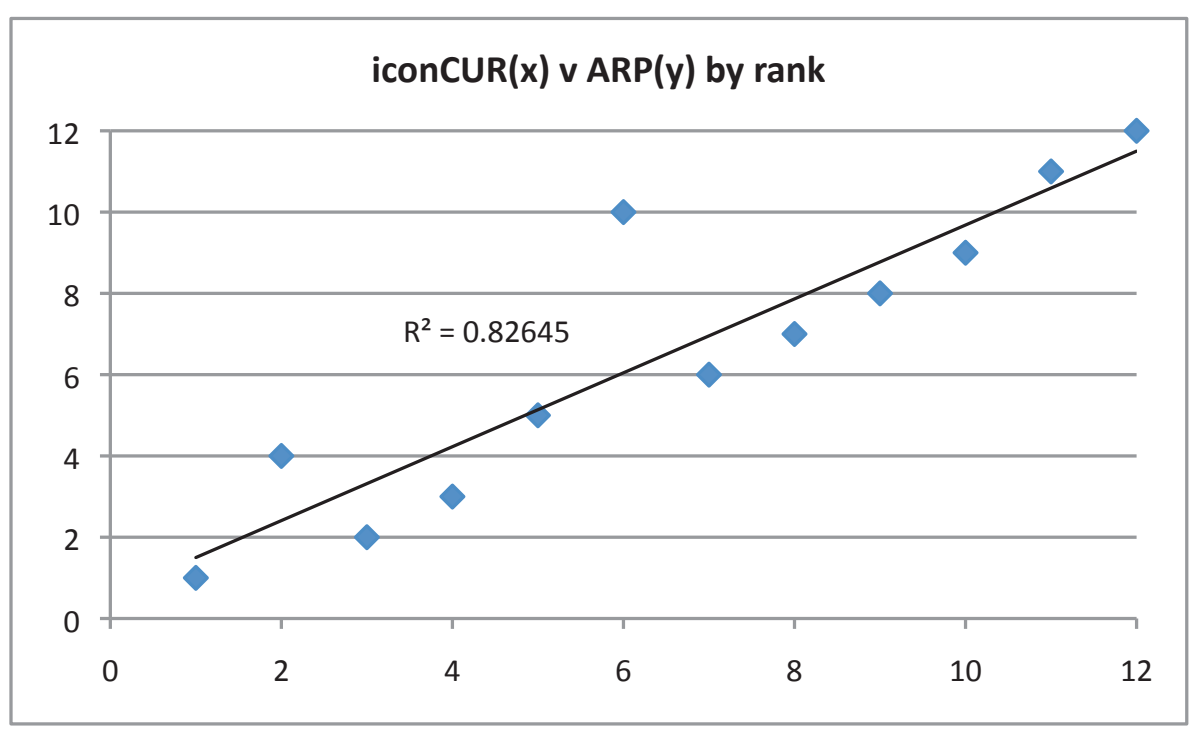

Figure VII: Correlation between iconCUR and ARP ranks 


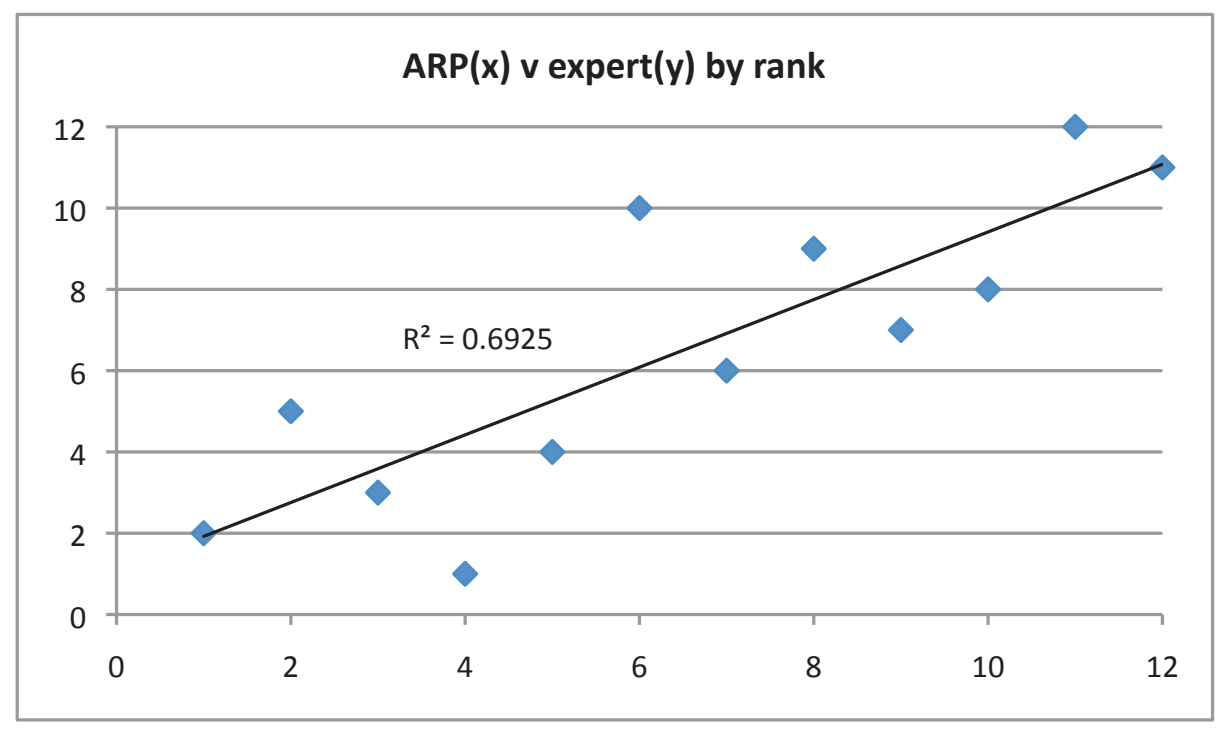

Figure VIII: Correlation between ARP and expert ranks 


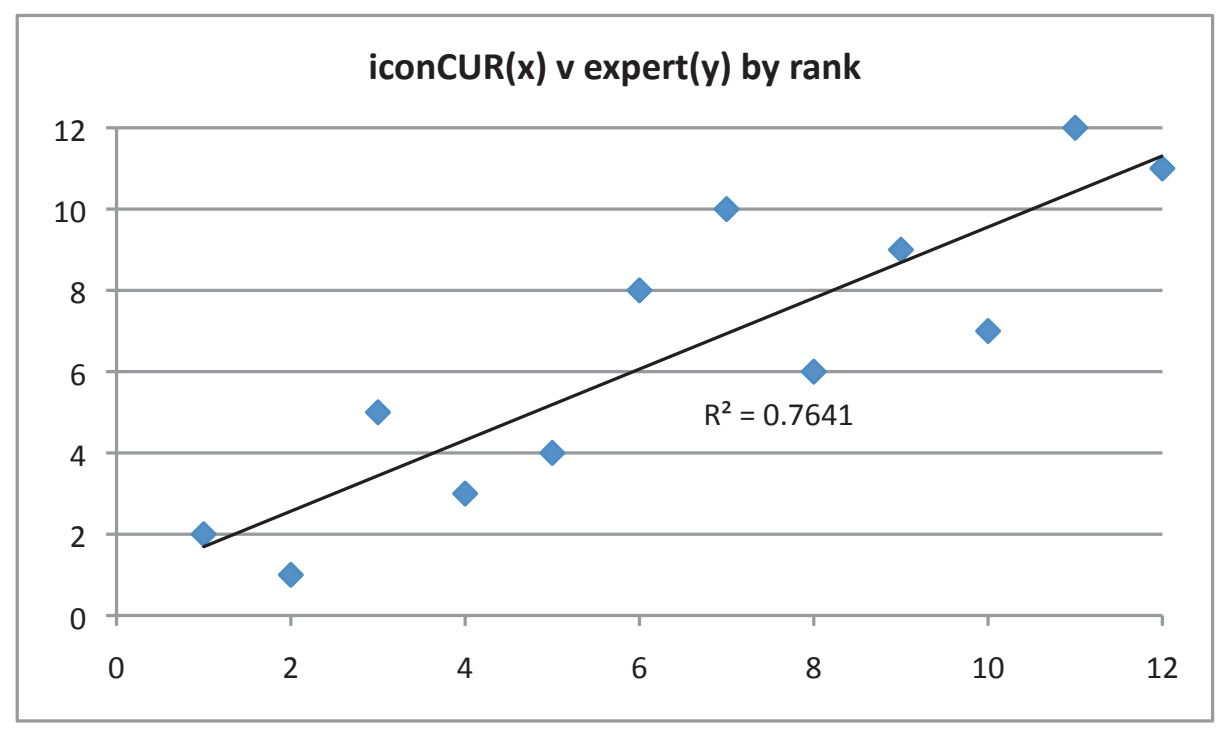

Figure IX: Correlation between iconCUR and expert ranks 
Table III: Summary of results (sorted by reward)

\begin{tabular}{|c|c|c|c|c|c|c|c|}
\hline \multirow{2}{*}{$\begin{array}{c}\text { Case Study } \\
\text { name }\end{array}$} & \multirow{2}{*}{$\begin{array}{c}\text { Outcome } \\
\text { trending decision }\end{array}$} & \multicolumn{3}{|c|}{ Modeling } & \multicolumn{3}{|c|}{ Rank } \\
\hline & & iconCUR ${ }^{*}$ & $A R P$ & reward & iconCUR & $A R P$ & team \\
\hline Warrnambool & retain/extend & 4.76 & 6.1 & 2.86 & 11 & 11 & 12 \\
\hline Hawthorn & retain/extend & 4.66 & 27.6 & 2.58 & 9 & 8 & 9 \\
\hline Brunswick & retain/extend & 4.14 & 14.1 & 2.49 & 6 & 10 & 8 \\
\hline Mildura & reuse/adapt & 3.19 & 73.4 & 2.46 & 1 & 1 & 2 \\
\hline Swan Hill & reuse/adapt & 3.76 & 64.0 & 2.38 & 3 & 2 & 5 \\
\hline Kyneton & reuse/adapt & 3.90 & 56.3 & 2.27 & 4 & 3 & 3 \\
\hline Heidelberg (hall) & renovate/preserve & 4.62 & 31.2 & 2.09 & 8 & 7 & 6 \\
\hline Heidelberg (drop-in centre) & renovate/preserve & 4.69 & 21.5 & 2.04 & 10 & 9 & 7 \\
\hline Maffra & reuse/adapt & 3.48 & 49.4 & 2.02 & 2 & 4 & 1 \\
\hline Bendigo & reuse/adapt & 3.92 & 42.3 & 2.01 & 5 & 5 & 4 \\
\hline Keilor & reconstruct/dispose & 4.55 & 35.5 & 1.86 & 7 & 6 & 10 \\
\hline Rutherglen & reconstruct/dispose & 5.39 & 0.0 & 1.55 & 12 & 12 & 11 \\
\hline & & * distance & adapt & reuse $c$ & $\operatorname{rner}(5,0,5)$ & & \\
\hline
\end{tabular}

